\title{
RESEARCH
}

Open Access

\section{The shape of chiropractic in Europe: a cross sectional survey of chiropractor's beliefs and practice}

\author{
Halldór Fannar Gíslason ${ }^{1}$, Jari Kullervo Salminen², Linn Sandhaugen ${ }^{3}$, Andreas Stenseth Storbråten ${ }^{3}$,
} Renske Versloot ${ }^{4}$, Inger Roug ${ }^{5}$ and Dave Newell ${ }^{5^{*}}$ (D)

\begin{abstract}
Background: The chiropractic profession both in the past and presently has diverse opinions concerning different health care approaches and the science or otherwise that underpins them. Previous research has reported that adherence to unorthodox descriptions of chiropractic were associated with types of practice behavior considered outside of acceptable evidence-based guidelines in Canada. However, this type of investigation has not been repeated in a European context and such relationships may be different.
\end{abstract}

Methods: A survey was disseminated amongst European chiropractors during early 2017. Dissemination was through an on-line platform with links to the survey being sent to all European chiropractic associations regardless of European Chiropractors' Union (ECU) membership and additionally through the European Academy of Chiropractic (EAC). Social media via Facebook groups was also used to disseminate links to the survey.

Results: One thousand three hundred twenty and two responses from chiropractors across Europe representing approximately $17.2 \%$ of the profession were collected. Five initial self-determined chiropractic identities were collapsed into 2 groups categorised as orthodox (79.9\%) and unorthodox (20.1\%). Analysis of responses to a range of questions stratified by such groups was carried out. When comparing the percentage of new patients chiropractors $x$-rayed, $23 \%$ of the unorthodox group x-rayed $>50 \%$ of their new patients compared to $5 \%$ in the orthodox group. Furthermore, the proportion of respondents reporting > 150 patient encounters per week in the unorthodox group were double compared to the orthodox $(22 \vee 11 \%)$. Lastly the proportion of those respondents disagreeing or strongly disagreeing with the statement "In general, vaccinations have had a positive effect on global public health" was 57 and $4 \%$ in unorthodox and orthodox categories respectively. Logistic regression models identified male gender, seeing more than 150 patients per week, no routine differential diagnosis, and not strongly agreeing that vaccines have generally had a positive impact on health as highly predictive of unorthodox categorisation.

Conclusions: Despite limitations with generalisability in this survey, the proportion of respondents adhering to the different belief categories are remarkably similar to other studies exploring this phenomenon. In addition, and in parallel with other research, this survey suggests that key practice characteristics in contravention of national radiation guidelines or opposition to evidence based public health policy are significantly more associated with non-orthodox chiropractic paradigms.

Keywords: Orthodox, Non-orthodox, Chiropractic, Practice, Beliefs, Paradigms

\footnotetext{
* Correspondence: dnewell@aecc.ac.uk

${ }^{5}$ AECC University College, Parkwood Road, Bournemouth, England, UK

Full list of author information is available at the end of the article
}

(c) The Author(s). 2019 Open Access This article is distributed under the terms of the Creative Commons Attribution 4.0 International License (http://creativecommons.org/licenses/by/4.0/), which permits unrestricted use, distribution, and reproduction in any medium, provided you give appropriate credit to the original author(s) and the source, provide a link to the Creative Commons license, and indicate if changes were made. The Creative Commons Public Domain Dedication waiver (http://creativecommons.org/publicdomain/zero/1.0/) applies to the data made available in this article, unless otherwise stated. 


\section{Background}

The history of the chiropractic profession is one characterised by a trajectory from early theories that attempted to explain the improvements seen during chiropractic care to increasingly embracing modern science, research methodology and evidence.

However, the profession has not made this journey in unison. The present state might reasonably be characterised as a spectrum of ideas within which two broad and polarised explanatory frameworks exist to explain positive outcomes seen in practice [1]. The degree of adherence to these paradigms varies across chiropractic institutions and geographical jurisdictions and has been studied previously [2-4]. One paradigm is characterised by a broad group of descriptions as to how chiropractic care generates patient outcomes seen in practice. These range from a musculoskeletal and structurally focused explanation [5], more neurological emphases [6] to broad ideas around prevention and wellness. Whilst it is unlikely that any of these explanations are uniquely true descriptions of the mechanisms by which patients improve they either have some evidential support or at the very least provide biologically plausible explanations. An alternative group of paradigms hold more strongly to historical ideas and theories espoused at the inception of the profession. A proportion of the profession still consider these theories and explanatory frameworks to be relevant either as described by the original unabridged teachings of the Palmers or merged together with a mix of scientific, pseudo-scientific and philosophical elements that is described in some quarters as constituting a new healthcare paradigm. To some degree or another this unorthodox explanatory framework has its roots in vitalism [7] and is centred on the body's ability to heal itself if theorised barriers to such healing are removed. Amongst legitimate ideas within this paradigm are those such as addressed in mainstream public health initiatives including healthy eating and increased activity. However, this paradigm is also associated with less evidenced impediments to health such as spinal neuro-biomechanical lesions described as subluxations $[8,9]$.

Strong vitalistic versions of this explanatory framework propose a life force (Innate Intelligence) that is theorised to be carried by the nervous system [7]. This belief includes the idea that manipulating the spine to remove restrictions or 'chiropractic subluxations' can restore health and some chiropractors see themselves as the only individuals who can identify and remove such restrictions through unique 'chiropractic manipulations' and restoring the full expression of such a life force. Despite a fundamental lack of supporting scientific evidence for this position, subgroups within the chiropractic profession continue to adhere to this or similar explanatory frameworks $[2,4]$.
A recent survey of Canadian chiropractors reported that around $18 \%$ of Canadian chiropractors chose such a vitalistic description to characterise what they do [2] and that such self-categorisation was also associated with unorthodox practices. Furthermore, a follow up study confirmed that such beliefs and ideologies were associated with a small subsection of US based chiropractic educational programs [4].

This study aimed to repeat such a survey within Europe as no data exists regarding such categorisation of beliefs or potential association with unorthodox practice.

\section{Methods}

\section{Design and piloting}

The survey instrument used in this study was a modified version of the original questionnaire [2]. Following a face validity study conducted amongst AECC University College faculty the structure of the questionnaire was altered in response to the majority of participants indicating a number of questions with the same emphasis. Specifically, an alteration made was regarding the original option [2] "I treat a combination of general problems and biomechanical conditions" (Biomechanical/General problems) which was removed due to similarities to "I treat musculoskeletal or neuromusculoskeletal problems and may include specific disorders such as but not limited to low back and neck-related pain" (Biomechanical) thus creating 5 chiropractic descriptions from the original 6.

\section{Dissemination}

The survey was administered via Survey Monkey and distributed via consenting European national chiropractic associations. In addition, survey links were distributed extensively within a range of chiropractic Facebook groups. In addition, the European Academy of Chiropractic also assisted with distribution to its European members. Three reminders were sent to associations who didn't confirm participation. All associations and the EAC were sent 2 e-mails to remind members to complete the survey between January 2017 and March 2017. One re-post of the survey in FB groups was also carried out to encourage participation.

\section{Target population}

All chiropractors that were practicing in Europe at the time of the survey and capable of understanding and interpreting the English language were allowed to participate in this study. All chiropractors practicing outside of Europe were excluded from participation. This was achieved during data cleaning noting the 'country' question response in the survey. No compensation was offered to the participants. Because access to the entire population through a single e-mail list was not available sample randomisation was not possible. An introduction 
text at the beginning of the survey included information about confidentiality. "Will my taking part in the study be kept confidential? Yes, we will anonymize all data we collect and we will not include any person identifiably information in the write-up of the study".

\section{Orthodox/unorthodox subgrouping}

Orthodox and unorthodox categories were determined through a set of key questions (Table 1) within the survey with categories $1,2,3$ and 4 defined a priori as orthodox and 5 as unorthodox as in the original study [2].

\section{Statistical analysis}

Descriptive analysis was used to describe the respondents' characteristics and to determine any differences in responses between orthodox and unorthodox categories. In addition, a forward binary logistic regression model was used to model factors within the survey instrument that predicted membership of the unorthodox category. Countries with less than a hundred chiropractors according to the latest European Chiropractors' Union (ECU) figures (personal communication, 12 June 2017) and countries with a response rate less than $10 \%$ were excluded from the country analysis.

\section{Results}

All European associations, both members of the ECU and non member associations $(n=37)$ were approached. Of these, e-mails were received from 15 associations confirming participation. Only one association specifically declined to participate.

Thirteen hundred and twenty-two $(N=1322)$ chiropractors returned completed questionnaires. This constituted a $17.2 \%$ return rate based on estimated figures of 7680 chiropractors in 2017 (personal communication, 12 June 2017).

Table 2 shows the general demographic characteristics of the respondents indicating a skewing toward male practitioners at the level of survey respondents. Most

Table 1 Which ONE of the following best describes the predominant view you have of the conditions you treat?

1. I treat musculoskeletal and neuromusculoskeletal problems and include specific disorders such as but not limited low back and neck related pain.

2. I treat the broadest spectrum of health concerns and may include lifestyle and wellness issues.

3. I treat vertebral subluxation as a somatic joint dysfunction and/or related to functional or musculoskeletal problems.

4. I treat a combination of biomechanical and organic/visceral complaints.

5. I treat vertebral subluxation as an encumbrance to the expression of health - vertebral subluxation is seen as an entity in and of itself, which is corrected to benefit patient well-being.
Table 2 Characteristics of respondents $(N=1322)$

\begin{tabular}{lll}
\hline Variables & N (\%) & Mean (SD) \\
\hline Gender (M) & $835(63.2)$ & - \\
Previous degree & & - \\
Secondary school & $553(42.1)$ & - \\
University Degree & $461(35.1)$ & - \\
Master's Degree & $94(7.2)$ & - \\
PhD & $12(0.9)$ & - \\
Other & $124(9.5)$ & - \\
Age & & - \\
$20-29$ & $200(15.4)$ & - \\
$30-39$ & $406(31.2)$ & - \\
$40-49$ & $361(27.7)$ & - \\
$50-59$ & $225(17.3)$ & - \\
$60-69$ & $90(6.9)$ & $14.4(10.8)$ \\
$>70$ & $19(1.5)$ & \\
Years in practice & - &
\end{tabular}

respondents entered chiropractic training from secondary school. However, over 1/3 entered with a University degree. The largest age group were 30 to 39 -year olds and the average career length was around 14 years. Less than $1 \%$ of the sample possessed a $\mathrm{PhD}$.

Returns were received from 23 European countries (Table 3). However, the return rates varied markedly with some countries with very few chiropractors such as Estonia and Portugal with high return rates while others with larger numbers such as Denmark and France returning very few.

Categories that described the chiropractors' views as to their practice and paradigm were a key element of this survey (Table 1) with Table 4 describing the proportions aligned with each description. The majority of chiropractors aligned with an MSK description of their practice $(54 \%)$ with a further $20 \%$ describing their practice as addressing broad spectrum of health concerns including wellness or viscerosomatic issues. Around 27\% included subluxation as part their practice description. However, $7 \%$ of these see the subluxation as a biomechanical lesion related to the MSK system leaving 20\% describing such subluxations in a vitalistic paradigm that sees these restrictions as an encumbrance to health in and of themselves. Given that this last category is unsupported within a scientific or evidence-based paradigm it was defined as unorthodox with the remaining descriptions defined as orthodox given the varying degrees of supportive evidence or biological plausibility [2]. Table 5 indicates the proportions of orthodox and unorthodox self-selection within each of the countries that passed the criteria of having at least 100 practicing chiropractors and who achieved a greater than $10 \%$ return rate. In 
Table 3 Return rate per country

\begin{tabular}{llll}
\hline Country & Respondents (N) & Total population & Return rate (\%) \\
\hline Austria & 1 & 2 & 50.0 \\
Belgium & $\mathbf{6 2}$ & $\mathbf{1 2 0}$ & $\mathbf{5 1 . 7}$ \\
Cyprus & 1 & 12 & 8.3 \\
Denmark & 41 & 879 & 4.7 \\
Estonia & 4 & 5 & 80.0 \\
Finland & 8 & 75 & 10.7 \\
France & 12 & 400 & 3.0 \\
Germany & $\mathbf{8 1}$ & $\mathbf{1 7 9}$ & $\mathbf{4 5 . 3}$ \\
Greece & 2 & 30 & 6.7 \\
Hungary & 5 & 6 & 83.3 \\
Iceland & 6 & 17 & 35.3 \\
Ireland & $\mathbf{4 6}$ & $\mathbf{1 3 0}$ & $\mathbf{3 5 . 4}$ \\
Italy & $\mathbf{4 4}$ & $\mathbf{4 0 0}$ & $\mathbf{1 1 . 0}$ \\
Liechtenstein & 2 & 5 & 40.0 \\
Malta & 1 & 7 & 14.3 \\
Norway & $\mathbf{1 5 1}$ & $\mathbf{8 0 0}$ & $\mathbf{1 8 . 9}$ \\
Portugal & 15 & 22 & 68.2 \\
Spain & $\mathbf{9 0}$ & $\mathbf{3 3 0}$ & $\mathbf{2 7 . 3}$ \\
Sweden & $\mathbf{1 3 9}$ & $\mathbf{8 0 0}$ & $\mathbf{1 7 . 4}$ \\
Switzerland & $\mathbf{1 1 9}$ & $\mathbf{2 6 9}$ & $\mathbf{4 4 . 2}$ \\
The Netherlands & $\mathbf{1 0 9}$ & $\mathbf{4 0 0}$ & $\mathbf{2 7 . 3}$ \\
Turkey & 3 & 7 & 42.9 \\
UK & $\mathbf{3 3 0}$ & $\mathbf{3 1 9 5}$ & $\mathbf{1 0 . 3}$ \\
\hline
\end{tabular}

* = personal communication ECU Data 2017, Bold= $>100$ chiropractors in country and $>10 \%$ return rate

this data the highest proportion of unorthodox categorisation was found in Spain with Italy and Germany ranking 2nd and 3rd respectively. A range of countries were characterised by unorthodox proportions around 15$20 \%$ with the lowest rates being found in Switzerland, Belgium and Norway respectively.

Tables 6 and 7 describe a univariate logistic regression analysis reporting significant variables associated with orthodox/unorthodox categories. In terms of respondent characteristics, being male and between 30 and 39 years

Table 4 Self-selected chiropractic subgroups

\begin{tabular}{lll}
\hline Chiropractic subgroup & $N(\%)$ & $\begin{array}{l}\text { Dichotomous } \\
\text { grouping }\end{array}$ \\
\hline General problems & $163(14.0)$ & Orthodox \\
Biomechanical & $628(54.0)$ & Orthodox \\
Biomechanical/Organic-Visceral & $57(4.9)$ & Orthodox \\
$\begin{array}{l}\text { Subluxation as a somatic } \\
\text { dysfunction }\end{array}$ & $81(7.0)$ & Orthodox \\
$\begin{array}{l}\text { Subluxation as an obstruction } \\
\text { to human health }\end{array}$ & $233(20.1)$ & Unorthodox \\
\hline
\end{tabular}

Table 5 Orthodox and unorthodox proportions in countries where $>100$ chiropractors and $>10 \%$ return rate was achieved

\begin{tabular}{lll}
\hline Country & $N(\%)$ Orthodox & $N(\%)$ Unorthodox \\
\hline Belgium & $51(92.7)$ & $4(7.3)$ \\
Germany $^{\mathrm{a}}$ & $43(66.2)$ & $22(33.8)$ \\
Ireland & $31(79.5)$ & $8(20.5)$ \\
Italy & $23(59.0)$ & $16(41.0)$ \\
Norway & $132(93.0)$ & $10(7.0)$ \\
Spain & $34(43.6)$ & $44(56.4)$ \\
Sweden & $101(82.8)$ & $21(17.2)$ \\
Switzerland & $102(90.3)$ & $11(9.7)$ \\
The Netherlands & $81(82.7)$ & $17(17.3)$ \\
UK & $236(80.0)$ & $59(20.0)$ \\
\hline
\end{tabular}

$\mathrm{a}_{54 \%}$ attended weekend course

of age doubled the odds of belonging to the unorthodox grouping whereas only practicing in one country reduced the risk of belonging to this group (i.e. practicing in more than one country increased the risk of unorthodox self-categorisation). In terms of practice characteristics, reporting more than 100 patient visits weekly, not performing differential diagnosis and providing routine $x$-rays for more than $20 \%$ of new patients predicted membership of the unorthodox group. Beliefs that include the idea that chiropractic intervention effects the cause of conditions such as colic, enuresis, otitis media and dysmenorrhea were also significantly associated with unorthodoxy. In terms of public health issues such as vaccination; referring patients to a website, suggesting patients do their own research, providing pros and cons or providing information against vaccination, all predicted increased likelihood of belonging to the unorthodox group compared to an evidenced based approach of referring patients for advice to appropriately qualified health care professionals. Additionally, anything other than strongly agreeing that vaccines have had a positive effect on public health also significantly increased odds of belonging to the unorthodox grouping.

Final regression models adjusting for all significant univariate variables were constructed without (Table 8) and with (Table 9) the country variable. Only in the regression model shown in Table 9 did we exclude countries with few chiropractors and/or participants (see Statistical Analysis in Methods section). Characteristics that predicted unorthodoxy in both models were being male, seeing more than 150 patients per week, no routine differential diagnosis, and not strongly agreeing that vaccines have generally had a positive impact on health. These models explained over $50 \%$ of the variance and provided robust discriminatory power as illustrated by a large area under the curve (AUC) value for both models. 
Table 6 Significant univariate practitioner and practice variables associated with unorthodox category

\begin{tabular}{lll}
\hline$N$ & OR $(95 \% \mathrm{Cl})$ & $\mathrm{p}$ \\
\hline
\end{tabular}

Practitioner Characteristics

\begin{tabular}{|c|c|c|}
\hline Female & 418 & 1.0 \\
\hline Male & 738 & 2.1 (1.5 to 3.0$)$ \\
\hline \multicolumn{3}{|l|}{ Age } \\
\hline $20-29$ & 170 & 1.0 \\
\hline $30-39$ & 372 & 1.6 (1.1 to 2.6$)$ \\
\hline $40-49$ & 316 & 1.3 (0.8 to 2.2 ) \\
\hline $50-59$ & 203 & $1.1(0.6$ to 1.8$)$ \\
\hline $60-69$ & 80 & $1.0(0.5$ to 2.1$)$ \\
\hline$>70$ & - & - \\
\hline \multicolumn{3}{|c|}{ Always practiced in single country } \\
\hline No & 296 & 1.0 \\
\hline Yes & 865 & 0.6 (0.4 to 0.8$)$ \\
\hline
\end{tabular}

Practice Characteristics

Country

$\begin{array}{ll}\text { Norway }^{*} & 142 \\ \text { Belgium } & 55 \\ \text { Germany } & 65 \\ \text { Ireland } & 39 \\ \text { Italy } & 39 \\ \text { Spain } & 78\end{array}$

Sweden $\quad 122$

Switzerland $\quad 113$

Netherlands $\quad 98$

UK 296

Weekly Patient visits

$\begin{array}{ll}0-50 & 372 \\ 51-100 & 456 \\ 101-150 & 163 \\ 151 \text { to } 200 & 61 \\ 201 \text { to } 250 & 23 \\ 251 \text { to } 300 & 19 \\ >300 & 17\end{array}$

Perform differential diagnosis

$\begin{array}{lll}\text { Yes } & 1028 & 1.0 \\ \text { No } & \mathbf{1 3 2} & \mathbf{1 1 . 8}(\mathbf{7 . 9} \text { to } \mathbf{1 7 . 6})\end{array}$

Proportion of new patients given $\mathrm{X}$ ray (\%)

\begin{tabular}{llll}
$0-5$ & 587 & 1.0 & \\
$6-20$ & 291 & $1.0(0.7$ to 1.4$)$ & 0.89 \\
$\mathbf{2 1 - 5 0}$ & $\mathbf{1 1 5}$ & $\mathbf{1 . 7}(\mathbf{1 . 1}$ to $\mathbf{2 . 6})$ & $\mathbf{0 . 0 4}$ \\
$\mathbf{5 1 - 8 0}$ & $\mathbf{4 0}$ & $\mathbf{3 . 8}(\mathbf{2 . 0}$ to $\mathbf{7 . 4})$ & $\mathbf{0 . 0 0}$ \\
$\mathbf{8 1 - 1 0 0}$ & $\mathbf{5 4}$ & $\mathbf{8 . 8}(\mathbf{4 . 8}$ to $\mathbf{1 5 . 9})$ & $\mathbf{0 . 0 0}$ \\
\hline
\end{tabular}

Significant variables in bold, ${ }^{*}=$ Norway had lowest proportion of unorthodox respondents and was used as the comparator, $-=$ too few numbers to calculate

0.00

0.00

0.00

0.00

0.00
Table 7 Significant beliefs associated with unorthodox category

\begin{tabular}{|c|c|c|c|}
\hline & $\mathrm{N}$ & OR $(95 \% \mathrm{Cl})$ & $\mathrm{p}$ \\
\hline \multicolumn{4}{|c|}{ Conditions for which treatment effects cause } \\
\hline \multicolumn{4}{|l|}{ Dysmenorrhea } \\
\hline No & 951 & 1.0 & \\
\hline Yes & 211 & $1.5(1.1$ to 2.1$)$ & 0.03 \\
\hline \multicolumn{4}{|l|}{ Enuresis } \\
\hline No & 955 & 1.0 & \\
\hline Yes & 207 & 1.7 (1.2 to 2.4$)$ & 0.00 \\
\hline \multicolumn{4}{|l|}{ Colic } \\
\hline No & 907 & 1.0 & \\
\hline Yes & 255 & $1.5(1.2$ to 2.0$)$ & 0.00 \\
\hline \multicolumn{4}{|l|}{ Otitis Media } \\
\hline No & 959 & 1.0 & \\
\hline Yes & 203 & $1.6(1.1$ to 2.3$)$ & 0.00 \\
\hline \multicolumn{4}{|l|}{ Advice on vaccines } \\
\hline Suggest talk to an MD/Nurse & 363 & 1.0 & \\
\hline Refer to website (e.g. WHO) & 56 & $3.6(1.5$ to 8.9$)$ & 0.00 \\
\hline Provide information in support ${ }^{\Omega}$ & 70 & - & - \\
\hline Provide with pros and cons & 349 & $5.9(3.4$ to 10.4$)$ & 0.00 \\
\hline Suggest do their own research & 249 & $12.3(7.0$ to 21$)$ & 0.00 \\
\hline Provide information against & 63 & 40.0 (19.6 to 83$)$ & 0.00 \\
\hline \multicolumn{4}{|l|}{ Response to question } \\
\hline \multicolumn{4}{|c|}{$\begin{array}{l}\text { In general, vaccinations have had a positive effect on global public } \\
\text { health? }\end{array}$} \\
\hline Strongly agree & 300 & 1.0 & \\
\hline Agree & 335 & $30(1-224)$ & 0.00 \\
\hline Neutral & 266 & 91 (12 to 660$)$ & 0.00 \\
\hline Disagree & 155 & 259 (35 to 1894$)$ & 0.00 \\
\hline Strongly disagree & 92 & 618 (83 to 4616$)$ & 0.00 \\
\hline
\end{tabular}

$\Omega=$ zero cases in unorthodox category so unable to calculate, Significant variables in bold

\section{Discussion}

Contemporary opportunities afforded the chiropractic profession based on increasing alignment of guidelines and the scientific literature supporting the use of conservative care in the management of MSK conditions have been articulated previously [10]. However, to grasp such opportunities ongoing adherence to scientifically unsupported explanatory frameworks such as vitalism and the putative subluxation as a single impediment to health is increasingly untenable $[7,8,10]$. Indeed, such ongoing resistance to aligning with the scientific literature has been seen by some $[8,11-13]$ as the central issue in impeding professional legitimisation, scientific and societal support and inclusion within the wider health care professional landscape. Whilst professional legitimacy is probably high on the agenda of the chiropractic profession as a whole, such aims are counterfactual to 
Table 8 Overall regression model for belonging to unorthodox category (without Country)

\begin{tabular}{|c|c|c|}
\hline Variables in the equation & OR (95\% Confidence Interval) & $p$ \\
\hline Male & 1.8 (1.1 to 2.8$)$ & 0.01 \\
\hline \multicolumn{3}{|l|}{ Weekly Patient number } \\
\hline $151-200$ & $2.3(1.0$ to 5.0$)$ & 0.04 \\
\hline $201-250$ & $4.4(1.2$ to 15.9$)$ & 0.02 \\
\hline $251-300$ & $14.4(1.9$ to 109$)$ & 0.01 \\
\hline$>300$ & $5.1(1.2$ to 21.8$)$ & 0.03 \\
\hline$\%$ of new patient's x ray $(81-100)$ & $3.4(1.5$ to 7.5$)$ & 0.00 \\
\hline Perform differential diagnosis (No) & $3.8(2.2$ to 6.5$)$ & 0.00 \\
\hline Treatment effects cause of Enuresis (Yes) & 1.8 (1.1 to 2.9$)$ & 0.02 \\
\hline \multicolumn{3}{|l|}{ Vaccines Advice } \\
\hline Suggest do their own research & 2.1 (1.0 to 4.3$)$ & 0.04 \\
\hline Provide information against & 2.5 (1.1 to 6.4$)$ & 0.03 \\
\hline \multicolumn{3}{|l|}{ Response to question } \\
\hline \multicolumn{3}{|c|}{ In general, vaccinations have had a positive effect on global public health? } \\
\hline Agree & 18.6 (2.4 to 142$)$ & 0.00 \\
\hline Neutral & $33.9(4.4$ to 261$)$ & 0.00 \\
\hline Disagree & 82.5 (10.5 to 648$)$ & 0.00 \\
\hline Strongly Disagree & 134 (16.3 to 1103$)$ & 0.00 \\
\hline
\end{tabular}

Nagelkerke $=0.51$

$\mathrm{AUC}=0.89(95 \% \mathrm{Cl} ; 0.87$ to 0.92$)$

Table 9 Overall regression model for belonging to unorthodox category (with Country)

\begin{tabular}{|c|c|c|}
\hline Variables in the equation & OR (95\% Confidence Interval) & $\mathrm{p}$ \\
\hline Country (Italy) & $3.6(1.2$ to 11.3$)$ & 0.02 \\
\hline Male & $1.9(1.2$ to 3.1$)$ & 0.01 \\
\hline \multicolumn{3}{|l|}{ Weekly Patient number } \\
\hline $101-150$ & $2.3(1.1$ to 4.5$)$ & 0.02 \\
\hline $151-200$ & $2.8(1.0$ to 6.8$)$ & 0.03 \\
\hline $201-250$ & 5.5 (1.3 to 22.7$)$ & 0.02 \\
\hline $251-300$ & $13.0(1.6$ to 105$)$ & 0.02 \\
\hline$>300$ & $6.0(1.2$ to 32.5$)$ & 0.04 \\
\hline Perform differential diagnosis (No) & 3.5 (1.9 to 6.3$)$ & 0.00 \\
\hline Treatment effects cause of Enuresis (Yes) & $2.0(1.1$ to 3.3$)$ & 0.01 \\
\hline \multicolumn{3}{|l|}{ Response to question } \\
\hline \multicolumn{3}{|c|}{ In general, vaccinations have had a positive effect on global public health? } \\
\hline Agree & 20.5 (2.7 to 155$)$ & 0.00 \\
\hline Neutral & 54.1 (7.2 to 404$)$ & 0.00 \\
\hline Disagree & 151 (20.0 to 1139) & 0.00 \\
\hline Strongly Disagree & 287 (36.0 to 2880$)$ & 0.00 \\
\hline
\end{tabular}


non-scientific explanatory frameworks which persistently underlie accusations of unorthodoxy amongst the professions detractors [14].

It is possible that such explanatory frameworks may be admissible as simple analogies at the patient level, particularly taking into account the impact of congruence of explanations with patient existing beliefs and expectations [15], the necessity of building therapeutic alliance $[16,17]$ and the likely impact of explanatory rationales [18] and contextual factors on outcomes [19]. However, it is unlikely that these non-orthodox explanatory frameworks have or will engender traction and/or confidence in the scientific and health professional landscape [20] particularly at interprofessional, political and funder levels. More importantly, where adherence to such paradigms is associated with practice-based behaviours that run counter to clinical guidelines, scientific evidence and a patient centred approach, particularly where fear is used to leverage compliance, arguments of the supposed benign if misguided nature of such beliefs as excused by some in the profession are untenable [21].

In this regard, the results of this study revealed a number of factors that significantly predict the alignment of a respondent in this survey with an unorthodox chiropractic paradigm. Of these factors, less favourable views regarding vaccination and increased frequency of the use of $\mathrm{x}$-rays with new patients were also described by McGregor et al. [2]. Additionally, a weekly patient load higher than 150 patients and opting not to perform a differential diagnosis also predict unorthodoxy although it is impossible to differentiate repeated visits by the same patients from high volumes of new patients.

Unlike in this study, 'not performing a differential diagnosis' was not explored by McGregor et al. [2]. This expectation is common in a European chiropractic educational context where clinicians are trained to generate or consider a differential diagnosis to guide further action. In some versions of chiropractic unorthodoxy clinicians do not see themselves as identifying or treating a condition or symptom, merely removing subluxations that they find. The association of unorthodoxy and lack of differential diagnosis in this study may be speculatively connected to such thinking.

Although unorthodox categorisation was associated with higher use of $x$-rays, no difference was found between the orthodox and unorthodox categories with regards to clinical justification for taking $x$-rays and the conditions treated. However, the results clearly indicate that unorthodox chiropractors tend to use $\mathrm{x}$-ray investigations on their patients more often than their orthodox counterparts. As to why this type of practise exists, more qualitative research may be illuminating. However, religiosity underpinning early rationales for the use of $\mathrm{x}$-rays have been suggested to be associated with ongoing adherence to such approaches [22]. Alternatively lack of knowledge of guidelines may underlie such behaviour and it is possible that educational interventions may change this behaviour [23]. Lastly, it is important to note that in some areas where chiropractors practice, a significantly older demographic may exist and this may precipitate a more risk averse approach to care that includes greater frequency of imaging as a precautionary stance. However, it is unlikely that those falling into the unorthodox group were differentially located within such demographics compared to the orthodox group and therefore this factor would not explain the greater use of $\mathrm{x}$-rays amongst the unorthodox group.

Vaccination is presently part of a major public health debate. Whilst most clinicians across healthcare acknowledge overwhelming evidence of the benefits versus risk of vaccination programs this is not universally the case in all professions. In chiropractic some groups in the profession are closely associated with key campaigns and figures in what has become known as the 'antivax' community [24], with some studies reporting low future commitment of uptake amongst chiropractors of vaccination [25].

The reasons behind this are unclear and the question remains as to why chiropractors hold strong opinions on vaccinations when it is not their area of expertise or scope of practice. Lack of support for vaccinations in this study was highly correlated with alignment to the 'vitalistic' paradigm as articulated by the unorthodox option in the survey. Such vaccination scepticism has been found previously in chiropractic students [26]. Perhaps the idea that the body is ultimately able to self-heal if impediments such as subluxations are removed leads to a type of thinking that sees vaccinations as external and 'unnatural' barriers to the bodies self-healing process. In this sense then, despite the belief having little if any scientific basis it may be expected, if not excused, within the context of a vitalistic paradigm. Despite understanding why these views may be held, the impact of failing vaccination uptake is far from trivial with a growing number of outbreaks of previously uncommon viral infections postulated to being associated with dropping vaccine adherence [27] impacted by antivax campaigns, particularly false claims around the aetiology of autism $[28,29]$. Whilst there may be a legitimate debate around the timing and cost effectiveness of some vaccinations, there is overwhelming scientific support for high benefit versus harm [30] and no scientific support for the idea that MMR causes autism [31]. In the face of this scientific consensus, chiropractors views concerning supposed danger of vaccinations are unfounded and if passed on to patients, run counter to the expected behaviour of health care professionals.

There are clear limitations to this study. McGregor et al. [2] used a randomisation process to generate a 
smaller target sample, which increased their response rate and likely generalisability. In comparison, the inability to use this approach in this study and the relatively low response rate has the potential to compromise the generalisability of these results. Moreover, the potential unknown differences in dissemination to various subgroups through non participation by some associations may have also biased the responses. Lastly, erroneous indication of country of practice may have led to practitioners outside of Europe being included in the survey although we consider this to be unlikely to be large numbers.

However, despite the differences in response rate and sample size, results in this questionnaire were highly consistent with those obtained by other authors with $20.1 \%$ of the respondents identifying with the unorthodox views compared to the $18.8 \%$ in the original Canadian survey [2]. Additionally, other studies [32, 33] found a similar division when questioning chiropractors in the United States and chiropractors worldwide, where respectively 19.3 and $17.4 \%$ of practitioners aligned with the view suggesting the chiropractic subluxation as an encumbrance to the expression of health. Given the similarity to findings within surveys using methodology more likely to be generalizable to their populations, unless highly coincidental, may strengthen the possibility of representatitiveness in this study. In this context we also modified the original questions of the original survey and this may have reduced the validity of the result. However, again, the association between similar unacceptable practices and the unorthodox subgrouping found here and in McGregors' study [2] suggests that the predictive validity of our survey was likely maintained.

Regarding the inclusion/exclusion of countries included in part of the analysis, the authors made an arbitrary cut off of at least a hundred chiropractors within the country according to the latest ECU registry (personal communication, 12 June 2017) and an individual response rate per country of $10 \%$ or higher. This does not allow us to make robust conclusions regarding the other counties or the true state of proportions of these groups within a country, and these results must be treated with caution.

\section{Conclusions}

This study showed that around one fifth of European chiropractors completing this survey identified themselves with an a priori defined unorthodox description of chiropractic care. The data also showed a number of key predictive practice behaviours statistically associated with this unorthodox group, including higher use of $\mathrm{x}$-rays, higher patient visits, absence of differential diagnostic approaches and less favourable views regarding the benefits of vaccination. Being the first of its kind in Europe, this study provides a unique description of beliefs and behaviours associated with unorthodox descriptions of chiropractic practice and may ultimately assist in understanding how such stances effect clinical behaviour.

The future and identity of the profession remains under constant, even exigent debate. Some chiropractors aspire to a more integrated approach into mainstream health care, whereas others wish chiropractic to remain sovereign, even antithetic to mainstream healthcare. Unfortunately, the chiropractic profession continues to engage in an internal battle around orthodox and unorthodox paradigms which has and continues to impede progression towards inclusion in a modern multidisciplinary health care setting and social and cultural legitimacy. Perhaps it is up to emerging generations of chiropractic students to find a solution to this schism [34] if the profession is to flourish and avoid an increasing and perhaps fatal marginalisation.

\section{Acknowledgements}

The authors would like to thank all the European chiropractors who took the time to participate in this survey and the other organisations that helped facilitate the data collection and provided information.

\section{Funding}

No funding was sought or given for this project.

Availability of data and materials

To date we do not have mechanisms for making data available on our institutional repository.

\section{Author Permission}

All authors have consented to publication.

\section{Authors' contributions}

DN conceived of the study, wrote the final drafts and performed statistical analysis, RV, HG, JS, LS and AS collected data and contributed toward the text and review of the draft manuscript. IR supervised the undergraduate project and contributed to review of the draft manuscript. All authors read and approved the final manuscript.

Ethics approval and consent to participate

This study was approved by via the AECC University College Ethics process. https://www.aecc.ac.uk/media/4012/research_ethics_policy_approved_june_ 2016_uc.pdf . Participants were informed at the beginning of the survey that taking part in the survey was indication of consent to use anonymised data.

\section{Consent for publication}

All participants gave consent at the beginning of the survey for their anonymised data to be used.

\section{Competing interests}

The authors declare that they have no competing interests.

\section{Publisher's Note}

Springer Nature remains neutral with regard to jurisdictional claims in published maps and institutional affiliations.

\section{Author details}

${ }^{1}$ Reykjavik, Iceland. ${ }^{2}$ Tampere, Finland. ${ }^{3}$ Oslo, Norway. ${ }^{4}$ Wijchen, The Netherlands. ${ }^{5}$ AECC University College, Parkwood Road, Bournemouth, England, UK. 
Received: 15 October 2018 Accepted: 25 January 2019

Published online: 10 April 2019

\section{References}

1. Field J, Newell D. Clinical outcomes in a large cohort of musculoskeletal patients undergoing chiropractic Care in the United Kingdom: a comparison of self- and National Health Service-Referred Routes. J Manip Physiol Ther. 2016;(1):54-62.

2. McGregor M, Puhl A, Reinhart C, Injeyan, H, Soave D. Differentiating intraprofessional attitudes toward paradigms in health care and delivery among chiropractic factions: results from a randomly sampled survey. BMC Complement Altern Med 2014; 14:51-51.

3. Gliedt J, Hawk C, Anderson M, Ahmad K, Bunn D, Cambron J, Gleberzon B, Hart J, Kizhakkeveettil A, Perle S, Ramcharan M, Sullivan S, Zhang L. Chiropractic identity, role and future: a survey of north American chiropractic students. Chiropr Man Therap. 2015;23(4).

4. Puhl A, Reinhart C, Doan J, McGregor M, Injeyan S. Relationship between chiropractic teaching institutions and practice characteristics among Canadian doctors of chiropractic: a random sample survey. J Manip Physio Ther. 2014:34(9):709-18.

5. Nelson C, Lawrence J, Triano J, Bronfort G, Perle S, Metz D, Hegetschweiler K, LaBrot T. Chiropractic as spine care: a model for the profession. Chiropractic \& Osteopathy. 2005;13(9)

6. Meyer AM, Leboeuf-Yde C. Unravelling functional neurology: a critical review of clinical research articles on the effect or benefit of the functional neurology approach. Chiropr Man Therap. 2018;26:30.

7. Keating J. The meanings of innate. J Can Chiropr Assoc. 2002;46(1):4-10.

8. Keating J, Charlton K, Grod P, Perle S, Sikorski D, Winterstein F. Subluxation: dogma or science? Chiropractic \& Osteopathy. 2005;13(17).

9. Huijbregts P. The chiropractic subluxation: implications for manual medicine. J Man Manipulative Ther. 2005;13(3):139-41.

10. French SD, Downie AS, Walker BF. Low back pain: a major global problem for which the chiropractic profession needs to take more care. Chiropr Man Therap. 2018;26:28

11. Walker B. The new chiropractic. Chiropr Man Therap. 2016:24:26.

12. Reggars JW. Chiropractic at the crossroads or are we just going around in circles? Chiropr Man Therap. 2011;(1):11.

13. Goncalves G, Le Scanff C, Leboeuf-Yde C. Effect of chiropractic treatment on primary or early secondary prevention: a systematic review with a pedagogic approach. Chiropr Man Therap. 2018;26:10.

14. Newell D, Lewith G. Alternative, complementary or orthodox: what is real medicine? Eur J Pers Cent Healthc. 2016;4(3):467-71.

15. Bishop M, Bialosky J, Cleland J. Patient expectations of benefit from common interventions for low back pain and effects on outcome: secondary analysis of a clinical trial of manual therapy interventions. J Man Manip Ther. 2011;19(1):20-5.

16. Lambers $\mathrm{N}$, Bolton J. Perceptions of the quality of the therapeutic alliance in chiropractic care in the Netherlands: a cross-sectional survey. Chiropr Man Therap. 2016;24:18.

17. Ferreira P, Ferreira M, Maher C, Refshauge K, Latimer J, Adams R. The therapeutic alliance between clinicians and patients predicts outcome in chronic low back pain. Phys Ther. 2013;93(4):470-8.

18. Locher C, Frey Nascimento A, Kirsch I, Kossowsky J, Meyer A, Gaab J. Is the rationale more important than deception? A randomized controlled trial of open-label placebo analgesia. Pain. 2017;158(12):2320-8.

19. Newell D, Lothe L, Raven T. Contextually aided recovery (CARe): a scientific theory for innate healing. Chiropr Man Therap. 2017;25(6).

20. Simpson K. The five eras of chiropractic \& the future of chiropractic as seen through the eyes of a participant observer. Chiropr Man Therap. 2012;20(1).

21. Simpson K. Appeal to fear in health care: appropriate or inappropriate? Chiropr Man Therap. 2017:25:27.

22. Young K. Gimme that old time religion: the influence of the healthcare belief system of chiropractic's early leaders on the development of x-ray imaging in the profession. Chiropr Man Therap. 2014;22:36

23. Ammendolia C, Hogg-Johnson S, Bombardier C, Pennick V, Glazier R. Implementing evidence-based guidelines for radiography in acute low Back pain: a pilot study in a chiropractic community. J Manip Physiol Ther. 2004; 27(3):170-9

24. Lee B. Are chiropractors backing the anti-vaccine movement? FORBES, Dec. 10, 2016, http://www.forbes.com/sites/brucelee/2016/12/10/are- chiropractors-backing-the-anti-vaccine-movement/\#3bd3e3f15db6 (Accessed Sept 18, 2018).

25. Medd E, Russell M. Personal and professional immunization behaviour among Alberta chiropractors: a secondary analysis of cross-sectional survey data. J Manip Physiol Ther. 2009;32(6):448.

26. Bussea J, Wilson K, Campbell J. Attitudes towards vaccination among chiropractic and naturopathic students. Vaccine. 2008;26(49):6237-43.

27. Varun K, Phadke M, Robert A, Bednarczyk M, Salmon D, Saad B. Association between vaccine refusal and vaccine-preventable diseases in the United States. JAMA. 2016;315(11):1149-58.

28. Mavragani A, Ochoa $\mathrm{G}$. The internet and the anti-vaccine movement: tracking the 2017 EU measles outbreak. Big Data and Cognitive Computing. 2018;2(1):2.

29. Gleberzon B, Lameris M, Schmidt C, Ogrady J. On Vaccination \& Chiropractic: when ideology, history, perception politics and jurisprudence collide. J Can Chiropr Association. 2013;57(3):205-13.

30. Rabinowitz M, Latella L, Stern C, Jost JT. Beliefs about childhood vaccination in the United States: political ideology, false consensus, and the illusion of uniqueness. PLoS One. 2016;11:e0158382.

31. Taylor L, Swerdfeger A, Eslick G. Vaccines are not associated with autism: an evidence-based meta-analysis of case-control and cohort studies. Vaccine. 2014:32(29):3623-9.

32. McGregor M. Jurisdictional control of conservative spine care: chiropractic versus medicine. University of Texas: Thesis (PhD); 2006.

33. McDonald W, Durkin K, Pfefer M. How chiropractors think and practice: the survey of north American chiropractors. Seminars Integr Med. 2004:2(3):92-8.

34. Strahinjevich $B$, Simpson $K$. The schism in chiropractic through the eyes of a 1st year chiropractic student. Chiropr Man Therap. 2018;26(2).

\section{Ready to submit your research? Choose BMC and benefit from:}

- fast, convenient online submission

- thorough peer review by experienced researchers in your field

- rapid publication on acceptance

- support for research data, including large and complex data types

- gold Open Access which fosters wider collaboration and increased citations

- maximum visibility for your research: over $100 \mathrm{M}$ website views per year

At $\mathrm{BMC}$, research is always in progress.

Learn more biomedcentral.com/submissions 